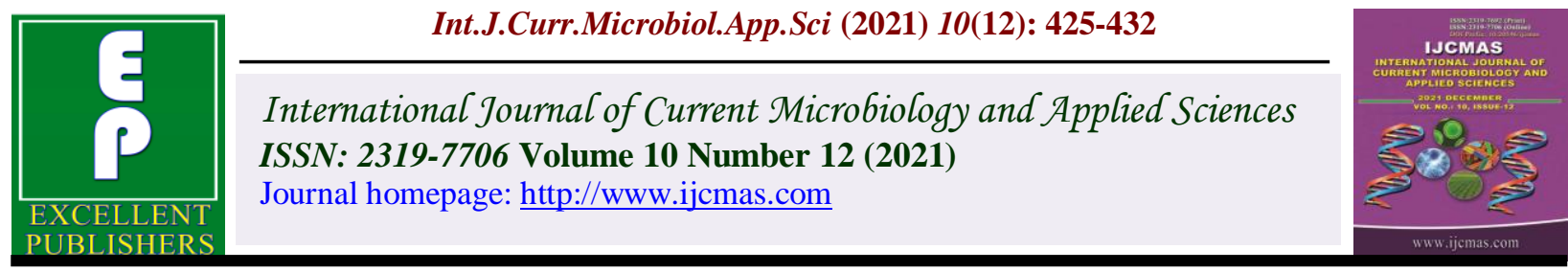

Review Article

https://doi.org/10.20546/ijcmas.2021.1012.047

\title{
Antimicrobial Resistance in Poultry Sector in India
}

\author{
Pooja Raizada, Jaya Chandawat, Roli Khanna, Sukriti Jaspal, \\ Anupa Siddhu and Aparna Agarwal
}

Department of Food and Nutrition and Food Technology, Lady Irwin College, University of Delhi, New Delhi, India

*Corresponding author

\section{A B S T R A C T}

Keywords

Antibiotic,

antifungal, antiviral, antibiotic growth promoters

\section{Article Info}

\section{Received:}

11 November 2021

Accepted:

05 December 2021

Available Online:

10 December 2021
Misuse and overuse of antimicrobials has led to antimicrobial resistance (AMR) and the outbreak of drug-resistant pathogens, which is acknowledged as the greatest hazard to humankind. The vast majority of antibiotics used are administered to farm animals. This is accelerating the evolution of antibiotic resistant bacteria. Increasing demand for protein supplements and animal protein by today's accelerating fitness industry and by the emerging number of fitness freaks is one of the most contributing factors for developing antimicrobial resistance. This is accelerating the evolution of antibiotic resistant bacteria. According to $\mathrm{WHO}$, the new diseases that have evolved and affected humans in the past 15-20 years are majorly those of animal origin (such as Avian influenza. H5N1) Lack of sanitation, and inadequate prevention and control of infections may promote the spread of microbes resistant to antimicrobial treatment. Therefore, use of antimicrobials should be scrutinized in order to establish an effective set of laws and regulations to safeguard not only the well-being of the population but also for the economic stability of a country.

\section{Introduction}

Antimicrobials are substances used to prevent and treat infections in humans, animals, and plants. These can be antibiotic, antifungal, antiviral, or antiparasitic based on the target microbe (i.e., bacteria, viruses, fungi, and parasites) ${ }^{(1)}$. The use of antibiotics in foodproducing animals is not just limited to treat infections, antibiotics are administered for metaphylaxis (administration of antibiotics to animals when anticipated to have contacted a diseased animal), prophylaxis (mass administration of antibiotics to animals to prevent disease when risk is established) and as antibiotic growth promoters (AGP's) to boost feed efficiency and increase in weight gain ${ }^{(2)}$. Antimicrobials as growth promoters were first added in chicken and pig feed by Moore and Stokstad in the mid -1950's ${ }^{(3)}$. 
Poultry is one of the fastest-growing sectors in India owing to an increase in the income of the population and the emergence of vertically integrated poultry producers. India stands fifth and eighteenth in terms of egg and broiler production respectively ${ }^{(7)}$. India accounts for about $3 \%$ of the global consumption of antimicrobials in food animals (Florence Mutua, 2020) ${ }^{(4)}$. A surge in antimicrobial resistance due to the unprecedented use of antimicrobials in the poultry industry was reported by the Centre for Science and Environment (CSE).

CSE's Pollution Monitoring Laboratory in a study found that nearly $40 \%$ of the samples tested contained antibiotic residues of one or more antibiotics (Centre for Science and Environment, 2014). Antimicrobial resistance (AMR) is a major health problem worldwide (6). AMR occurs when microbes are no longer sensitive to drugs they originally were ${ }^{(4)}$. The first case of antibiotic resistance was reported in 1951 when turkey was fed by streptomycin (3). Misuse of antibiotics leads to the development of antibiotic-resistant bacteria in the animals as well as the farm. Moreover, when the human pathogenic bacteria are exposed to low levels of antibiotic residues over time, they may develop antibiotic resistance (Centre for Science and Environment, 2014).

Poultry is one of the most widely consumed meats and the Indiscriminate use of antibacterials in animal husbandry will hence accelerate the process of AMR ${ }^{(6)}$. The major foodborne bacterial pathogens known to infect raw poultry meat products and their processing environment are Listeria monocytogenes and Salmonella. The treatment of salmonellosis and listeriosis requires appropriate antimicrobial therapy and since food-borne pathogens have become resistant to regularly used antibiotics, the treatment of patients becomes difficult ${ }^{(5)}$.

\section{Antimicrobial Resistance in Poultry in India}

With $10.71 \%$ of the world's total livestock population, animal husbandry has proven to be of paramount importance for the economy of the country (Indian Federation of Animal Health Companies) ${ }^{(9)}$. According to Indian Journal of Medical Research, poultry consumption in India is expected to rise by $577 \%$ between 2000 and 2030 ${ }^{(11)}$ and according to a report by McKinsey and company, the per capita chicken consumption is set to grow from 3.2 to $9.1 \mathrm{Kg}$ by $2030^{(12)}$. Poultry being a cheaper protein source than others has the potential to increase production manifold leading to the abundant use of antimicrobial agents to enhance productivity (11). Often, subtherapeutic doses are administered as a precautionary measure in case the animals are at risk of developing a certain disease ${ }^{(10)}$. The poultry industry of India produces $1,916 \times 10$ tonnes of broiler meat per year with Haryana contributing to the major part in this production (18.4\%), West Bengal (17.1\%), and Uttar Pradesh (14.1\%). ESBL- producing Enterobacteriaceae studies, which are among the studies on AMR in poultry, have documented the rate of ESBL producers to vary from 9.4 percent in Odisha to 33.5 percent in Madhya Pradesh to 87 percent in Punjab. Other four studies reported the presence of Salmonella species in broilers to vary from 3.3 percent in Uttar Pradesh to 23.7 percent in Bihar in addition to 100 percent isolates being resistant to ciprofloxacin, gentamicin, and tetracycline in Bihar and West Bengal ${ }^{(11)}$.

Since poultry production requires less water for maintenance and has proven to be more beneficial in terms of income, farmers in the rural areas around Bangalore are gradually moving to poultry from crop production. Consequently, antibiotic input is also increased for treating various infections and 
diseases. An increase in poultry farming at a time of increasing local average temperature (predicted to rise between $1.8^{\circ} \mathrm{C}$ and $3.3^{\circ} \mathrm{C}$ in Karnataka by 2030 with respect to the baseline period 1961-90) is likely to result in increased incidences of heat stress-related morbidity ${ }^{(13)}$.

Heat stress is responsible for causing symptoms like diarrhea and reduced appetite that could be mistaken (by less experienced farmers) as infections that need antibiotic treatment ${ }^{(13)}$. In addition to this, heat stress causes immune-suppressing effects.

According to the observations of Bartlett and Smith, broilers subjected to heat stress had lower levels of total circulating antibodies, and lower IgM and IgG levels, both during primary and secondary humoral responses, leaving broiler chickens more susceptible to bacterial infections hence generating the need for antibiotics ${ }^{(14)}$.

Livestock and poultry are known to harbor various commensal, indicator, and pathogenic bacteria of zoonotic importance. Escherichia coli is one of the microorganisms particularly important in the widespread propagation of antimicrobial resistance. Pathogenic strains of E. coli may be either diarrheagenic or extraintestinal $^{(15)}$. Extraintestinal pathogenic E. coli (ExPEC) strains may cause urinary tract infection, meningitis, and septicemia in humans ${ }^{(16)}$. The intestines and environment of healthy chickens can serve as a source for ExPEC strains with zoonotic potential (17). Researchers have confirmed the role of poultry in fecal excretion of multidrugresistant, as well as ESBL-positive E. coli strains (S. Bhave et al., 2019) ${ }^{(18)}$.

Salmonella isolates resistant to clindamycin, oxacillin, penicillin, and vancomycin have been detected in poultry and their environment in north India. The samples were found to be sensitive to ampicillin, enrofloxacin, and colistin (Renu Singh et al., 2013) (19). Multidrug- resistant Salmonella isolates were encountered in chicken eggs obtained from poultry farms and various marketing channels in north India (Sangeeta Singh et al., 2010) (20). Normally birds are raised in open sheds due to which it is difficult to keep diseasecarrying rodents and insects away from them. So, farm hygiene and maintenance play an important role in reducing the chances of infections and thus the need for treatment ${ }^{(13)}$.

\section{Optimising the Use of Antimicrobials}

Food-borne diseases including both foodborne infections and food-borne intoxications are a major health and financial burden for a country. The Food Safety and Standards Authority of India (FSSAI) in a report estimated that food-borne diseases cost the Indian economy $\$ 15$ million a year ${ }^{(21)}$. In a developing country like India, most foodborne diseases go unreported (22). The emergence of bacteria that are resistant to drugs used in the treatment of food-borne diseases may prove to be fatal for public health and may lead to increased hospitalizations and treatment failures ultimately leading to the death of a vast majority of people ${ }^{(23)}$. Hence the use of antibiotics needs to be strictly regulated and optimized. Firm laws and regulations for the usage of antimicrobials in the food-processing sector can not only contain antimicrobial resistance but also put the country at an economic advantage, as we have observed in the case of Namibia. Namibia has successfully developed a strong export market for its beef since it introduced a ban for the usage of antimicrobials for growth promotion in animals. Amplified consumer demand for safe and nutritious, antibiotic-free meat proved to be an important factor for putting Namibia at an economic edge ${ }^{(24)}$. Another option can be to safeguard critically important antibiotics for human use. The World Health Organization 
has designated certain antimicrobial classes as "Highest Priority Critically Important Antimicrobials" for human medicine (WHO CIA LIST), these include Quinolones (well known for acting against Quinolone-Resistant Salmonella and E. coli in animals), Third and Higher Generation Cephalosporins (in animals, these act against CephalosporinResistant Salmonella and E. coli, and in man (especially children) are therapeutic for grave Salmonella and E. coli infections), Macrolides and Ketolides (in animals, these act against Macrolide-Resistant Campylobacter spp., especially in poultry where these act against Campylobacter jejuni. Quinolones are not approved for use in the treatment of children who have been seriously infected by Campylobacter. That is where Macrolides turn out to be useful), Glycopeptides (In animals producing food, Glycopeptides help protect against Glycopeptide-Resistant Enterococcus spp. In addition to being a remedy for enterococcal infections) and Polymyxins (In food-producing animals, Polymyxins act against plasmid-mediated polymyxin-resistant E. coli. In critically ill patients, these act against grave Enterobacteriaceae and Pseudomonas aeruginosa multiresistant infections). (World Health Organization (2019, May). Highest Priority Critically Important Antimicrobials).

\section{Addressing Antimicrobial Resistance}

The World Health Organization has been leading multiple initiatives to make the general public aware of the hazards posed by the unprecedented use of antimicrobials including the World Antimicrobial Awareness Week, The Global Antimicrobial Resistance Surveillance System (GLASS), Global Antibiotic Research and Development Partnership (GARDP) and Interagency Coordination Group on Antimicrobial Resistance (IACG $)^{(1)}$. Recognizing the growing concern over antimicrobial resistance in the country, the Government of India came up with various initiatives to contain the problem of antimicrobial resistance one of them being the establishment of the National Task Force on AMR Containment in the year 2010 which further led to the formulation of the National Policy to Contain Antimicrobial Resistance in 2011 following which in November 2014, the WHO Regional Committee Meeting urged the members to accelerate their efforts to contain AMR as outlined in the Jaipur Declaration and the South-East Asia Regional Strategy on Antimicrobial Resistance. The center of attention for the coordination and implementation of the Antimicrobial Resistance Programme is the National Center for Disease Control, New Delhi ${ }^{(25)}$. The National Treatment Guidelines for Antimicrobial Use in Infectious Diseases were published to assist hospitals in developing the local guidelines under which physicians can receive instruction ${ }^{(25)}$. Standardization of antibiotic usage guidelines, restricting the utilization of antibiotic drugs as over-thecounter medications, prohibiting or restricting the use of antibiotics for promotion of growth in livestock, and pharmacovigilance, including prescription audits that include antibiotic use within the hospital and community, were all mandated by the National Health Policy $2017^{(25)}$.

\section{Problems Associated with Unprecedented Use of Antimicrobials}

The major problems arising due to unregulated use of antimicrobials are:

Increase in antimicrobial resistance - Misuse and overuse of antimicrobials have resulted in the development of resistant pathogens ${ }^{(26) .}$ Increase of the length of disease- due to antimicrobial resistance multiple regimes are ineffective in treatment and hence the need for longer hospitalization. 
Further, the need for longer hospitalization and the use of intensive care units (ICUs) and isolation beds to prevent the spread of the infection also add to the treatment cost. ${ }^{(26,27,28)}$

Increase of healthcare costs- AMR has a major impact on healthcare costs. Based on the study conducted by the center for disease control and prevention (CDC) in the United States, AMR can add up to $\$ 1,400$ to the hospital bill for treating patients with any bacterial infections. According to different studies, it is estimated that AMR cost could range from $\$ 300$ billion to more than $\$ 1$ trillion annually by 2050 worldwide. The increased cost can be mainly attributed to the use of expensive treatments and high resource utilization ${ }^{(28)}$.

Rise in mortality rate- By 2050, AMR could be causing 10 million deaths a year ${ }^{(29)}$. Currently, across the globe, approximately 700,000 people lose their lives because of drug- resistant infections each year ${ }^{(28)}$.

In India, according to a 2019 estimate, about 2 million people may die of antimicrobial resistance by 2050 . $^{(30,31)}$

Increase of more severe diseases- in India the consistently increasing non-communicable disease are also a matter of concern since these diseases are accompanied by a wide variety of infections that are cured by antibiotics in comparison to non-resistant bacteria the resistant forms will double the chances of developing a major disease and triple the chances of death $(30,28)$. Increase the risk of complications- Infections caused by resistant bacteria may be resistant to more than one antibiotic. For instance, previously used antituberculosis agents such as isoniazid and rifampicin are now less efficient. ${ }^{(26,27)}$

Increase of the risk of adverse effects, some being life-threatening-Antibiotics are responsible for around $20 \%$ of all drug-related emergency visits in the United States.

Out of which around $80 \%$ are due to allergic reactions and certain other conditions like gastrointestinal, neurologic, and psychiatric disorders. Most of these adverse effects are mild, but some life-threatening adverse effects have been witnessed, such as hepatotoxicity due to amoxicillin and clavulanate ${ }^{(26) .}$

Increase of re-attendance due to infectious diseases.

Increased medicalization

An indicator that monitors the occurrence of bloodstream infections due to two specific drug-resistant pathogens: methicillin-resistant Staphylococcus aureus (MRSA); and E. coli resistant to third-generation cephalosporins (3GC) was added in the Sustainable Development Goals (SDGs) system for surveillance in the year 2019. The data observed for their median ratewas- ${ }^{(1)}$

Antiviral drug resistance is most common in immunocompromised patients, where continuing virus replication and long-term drug exposure result in the selection of resistant strains. There are several antivirals to which resistance has grown, including antiretroviral (ARV) medications. ${ }^{(1)}$

Table.1

\section{Methicillin-resistant S. aureus \\ $E$. coli resistant to third-generation cephalosporins}

$11 \%$ (IQR 6.4-26.4)

36.0\% (IQR 15.2-63.0) 
Many fungal infections cause toxicity, making them difficult to manage, particularly in patients with other infections (e.g. HIV). Candida auris, one of the most prevalent invasive fungal infections, has already established drug resistance to fluconazole, amphotericin B, and voriconazole, along with evolving caspofungin resistance. As a result, fungal infections are becoming harder to cure, medication delays are becoming more likely, hospital stays are becoming longer, and treatment services are becoming much morecostly. ${ }^{(1)}$

Antimicrobial resistance is a common problem that all the countries of the world are facing right now, be it a developed country or a developing country. The continuous and rapid emergence of antibiotic-resistant pathogens has severely affected the country's medical systems and if stringent policies are not implemented, the pathogens that are resistant to antibiotics, especially multidrug-resistant bacteria, which are also known as 'superbugs' may cause harm to such an extent that the antibiotics will fail to treat the minutest of infections.

Optimizing the use of antimicrobials and stringent implementation of national and international initiatives.

\section{Acknowledgment}

Authors would like to acknowledge and thank Department of Biotechnology Star College Scheme and Department of Food technology, Lady Irwin College for funding and supporting the study.

\section{References}

1. World Health Organization. (2020, October 13). Antimicrobial Resistance. Antimicrobial Resistance-WHO. Retrieved January 27, 2021, fromhttps://www.who.int/news-room/factsheets/detail/antimicrobial-resistance

2. Walia K, Sharma M, Vijay S, Shome B R. Understanding policy dilemmas around antibiotic use in food animals \& offering potential solutions. Indian $\mathrm{J}$ Med Res. 2019;149(2):107-118.

doi:10.4103/ijmr.IJMR_2_18.

3. Feiyang Ma, S. X. (2021). Use of antimicrobials in food animals and impact of transmission of antimicrobial resistance in humans. Biosafety and Health,3238. $\{6\}$

4. Florence Mutua, G. S. (2020). A review of animal health and drug use practices in India, and their possible link to antimicrobial resistance. Antimicrobial Resistance and infection Control,9-103.

5. Abatcha, M. (2017). Salmonella and Listeria monocytogenes: A review of prevalence and antibiotic resistance in chickens and their processing environments. Advances in Animal Veterinary Sciences, 5(9),395-403.

6. Nhung $\mathrm{N}$ T, Chansiripornchai $\mathrm{N}$ and Carrique-Mas J J (2017) Antimicrobial Resistance in Bacterial Poultry Pathogens: A Review. Front. Vet. Sci. 4:126. doi: 10.3389/fvets.2017.00126.

7. Agricultural and Processed Food Products Export Development Authority (Ministry of Commerce and Industry, Government of India). (n.d.). Poultry Products. Retrieved August 21, 2021, from http://apeda.gov.in/apedawebsite/SubHead _Products/Poultry_Products.htm

8. Centre for Science and Environment. (2014, July 30). Antibiotics in Chicken. Retrieved August 21, 2021, from https://www.cseindia.org/latest-study-bycses- pollution-monitoring-lab-findsantibiotic-residues-in-chicken-8498

9. Indian Federation of Animal Health Companies. (n.d.). Animal Husbandry. Animal husbandry: Indian Federation of Animal Health Companies. Retrieved 
October

31 ,

2020

fromhttp://www.infah.org/animal-

health/animal-husbandry

10. Walia K, Sharma M, Vijay S, Shome B R. Understanding policy dilemmas around antibiotic use in food animals \& offering potential solutions. Indian $J$ Med Res. 2019;149(2):107-118.

doi:10.4103/ijmr.IJMR_2_18.https://www .ijmr.org.in/article.asp?issn=0971-

5916; year $=2019 ;$ volume $=149 ;$ issue $=2 ;$ spa ge $=107$; epage $=118$; aulast $=$ Walia

11. Taneja, N., \& Sharma, M. (2019). Antimicrobial resistance in the environment: The Indian scenario. The Indian journal of medical research, 149(2), $\quad 119$ 128.https://doi.org/10.4103/ijmr.IJMR_33 1_18

12. Department of Animal Husbandry, Dairying \& Fisheries Ministry of Agriculture \& Farmers Welfare Government of India, National Action Plan for Egg \& Poultry-2022 For Doubling Farmers' Income by 2022https://www.dahd.nic.in/sites/default/ filess/Seeking\%20Comments\%20on\%20 National\%20Action\%20Plan-\%20Poultry\%202022\%20by\%2012-12-2017.pdf

13. Poultry farming, climate change, and drivers of antimicrobial resistance in India Cole, Jennifer et al., The Lancet Planetary Health, Volume 3, Issue 12, e494 -e495. DOI: $\quad$ https://doi.org/10.1016/S25425196(19)30236-0

https://www.thelancet.com/journals/lanplh /article/PIIS2542-5196(19)302360/fulltext

14. Lara, L. J., \& Rostagno, M. H. (2013). Impact of Heat Stress on Poultry Production. Animals : an open access journal from MDPI, 3(2), 356369.https://doi.org/10.3390/ani3020356

15. Bauchart P, Germon P, Bree A, Oswald E, Hacker J, Dobrindt, U. (2010) Pathogenomic comparison of human extraintestinal and avian pathogenic Escherichia coli--search for factors involved in host specificity or zoonotic potential. MicrobPatho; 49: 105-115.

16. Belanger L, Garenaux A, Harel J, Boulianne M, Nadeau E, Dozois CM. (2011) Escherichia coli from animal reservoirs as a potential source of human extraintestinal pathogenic E. coli. FEMS Immunol Med Microbiol; 62: 1-10.

17. Ewers C, Antao E M, Diehl I, Philipp H C, Wieler L H. (2009) Intestine and environment of the chicken as reservoirs for extraintestinal pathogenic Escherichia coli strains with zoonotic potential. Appl Environ Microbiol 75:184-192.

18. Bhave, S., Kolhe, R., Mahadevaswamy, R., Bhong, C., Jadhav, S., Nalband, S.,... \& Muglikar, D. (2019). Phylogrouping and antimicrobial resistance analysis of extraintestinal pathogenic Escherichia coli isolated from poultry species. Turkish Journal of Veterinary and Animal Sciences, 43(1), 117-126.

19. Renu Singh, A. S. Yadav, V. Tripathi, R. P. Singh, Antimicrobial resistance profile of Salmonella present in poultry and poultry environment in north India, Food Control, Volume 33, Issue 2, 2013, Pages 545-548, ISSN 09567135,https://doi.org/10.1016/j.foodcont.20 13.03.041.

(https://www.sciencedirect.com/science/ar ticle/pii/S0956713513001631)

20. Sangeeta Singh, Ajit Singh Yadav, Satyendra Mohan Singh, Priyanka Bharti, Prevalence of Salmonella in chicken eggs collected from poultry farms and marketing channels and their antimicrobial resistance, Food Research International, Volume 43, Issue 8, 2010, Pages 2027-2030, ISSN 09639969,https://doi.org/10.1016/j.foodres.201 0.06.001.

(https://www.sciencedirect.com/science/ar ticle/pii/S0963996910002085). 
21. Sharma, P. (2020, October 15). Economic cost of food-borne disease is USD 15 billion per year in India: Health Ministry. ANI.https://www.aninews.in/news/nationa 1/general-news/economic-cost-of-foodborne-disease-is-usd-15-billion-per-yearfor-india-healthministry20201015165942/

22. National Center for Disease Control, Directorate General of Health Services, Government of India. (2017, March). Food Borne Diseases and Food Safety in India. National Center for Disease Control. Retrieved January 8, 2020, fromhttps://ncdc.gov.in/WriteReadData/li nkimages/CD\%20Alert4053017156.pdf

23. Antimicrobial resistance in the food chain. (2017, November). World Health Organization. Retrieved January 8, 2020, fromhttps://www.who.int/foodsafety/areas _work/antimicrobialresistance/amrfoodchain/en/

24. World Health Organization. (2017, November 14). Namibia's ban on antibiotics in healthy animals drives meat exports. Namibia's ban on antibiotics in healthy animals drives meat exports. Retrieved October 31, 2020, fromhttps://www.who.int/news$\mathrm{room} /$ feature-stories/detail/namibia-s-banon-antibiotics-in-healthy-animals-drives- meat-exports

25. Ministry of Health and Family Welfare, Government of India. (2017). National Action Plan on Antimicrobial Resistance.https://ncdc.gov.in/WriteRead Data/1892s/File645.pdf

26. Bjerrum, C. L. (2014). Antimicrobial resistance: risk associated with antibioticoveruse and initiatives to reduce the problem. TherAdv Drug Saf.,229-241.

27. Government of Canada. (2018, November 16). Antibiotic (Antimicrobial) Resistance. Retrieved January 30, 2021, fromhttps://www.canada.ca/en/publichealth/services/antibiotic-antimicrobialresistance.html

28. Dadgostar, P. (2019). Antimicrobial Resistance: Implications and Costs. InfectDrug Resist,3903-3910.

29. Sadasivan, S. (2020, February 29). The Week. Retrieved October 26, 2020, from THE

WEEK website:https://www.theweek.in/news/hea lth/2020/02/29/India-leading- the-way-inaverting-antibiotic-apoclypse.html

30. Karen L Tang, N. P. (2017). Restricting the use of antibiotics in food-producing animals. Lancet Planet Health, 1:e316-27.

31. Khachatourians, G. G. (1998). Agricultural use of antibiotics. Canadian Medical Association, 1129-1136.

\section{How to cite this article:}

Pooja Raizada, Jaya Chandawat, Roli Khanna, Sukriti Jaspal, Anupa Siddhu and Aparna Agarwal. 2021. Antimicrobial Resistance in Poultry Sector in India. Int.J.Curr.Microbiol.App.Sci. 10(12): 425-432. doi: https://doi.org/10.20546/ijcmas.2021.1012.047 